\title{
Multiresolution Wavelet Analysis of the Dynamics of a Cracked Rotor
}

\author{
Jerzy T. Sawicki, ${ }^{1}$ Asok K. Sen, ${ }^{2}$ and Grzegorz Litak ${ }^{3}$ \\ ${ }^{1}$ Department of Mechanical Engineering, Cleveland State University, 2121 Euclid Ave., Cleveland, OH 44115-2214, USA \\ ${ }^{2}$ Department of Mathematical Sciences, Indiana University, 402 N. Blackford Street, Indianapolis, IN 46202, USA \\ ${ }^{3}$ Department of Mechanics, Technical University of Lublin, Nadbystrzycka 36, 20-618 Lublin, Poland \\ Correspondence should be addressed to Jerzy T. Sawicki, j.sawicki@csuohio.edu
}

Received 17 December 2008; Revised 22 April 2009; Accepted 22 June 2009

Recommended by Agnes Muszynska

\begin{abstract}
We examine the dynamics of a healthy rotor and a rotor with a transverse crack, which opens and closes due to its self weight. Using discrete wavelet transform, we perform a multiresolution analysis of the measured vibration signal from each of these rotors. In particular, the measured vibration signal is decomposed into eight frequency bands, and the rms amplitude values of the healthy and cracked rotors are compared in the three lowest-frequency bands. The results indicate that the rms vibration amplitudes for the cracked rotor are larger than those of the healthy rotor in each of these three frequency bands. In the case of externally applied harmonic force excitation to the rotor, the rms values of the vibration amplitude of the cracked rotor are also found to be larger than those of a healthy rotor in the three lowest-frequency bands. Furthermore, the difference in the rms values between the healthy and cracked rotors in each of the three lowest-frequency bands is more pronounced in the presence of external excitation than that with no excitation. The obtained results suggest that the present multiresolution approach can be used effectively to detect the presence of a crack in a rotor.
\end{abstract}

Copyright ( $) 2009$ Jerzy T. Sawicki et al. This is an open access article distributed under the Creative Commons Attribution License, which permits unrestricted use, distribution, and reproduction in any medium, provided the original work is properly cited.

\section{Introduction}

Rotors used in industrial machinery such as compressors, pumps, or turbines are often subjected to extreme loading during their operation. Rotating parts in machines exposed to external forces and temperatures may lead to a fatigue crack resulting in rotor damage. Structural health monitoring of the rotors is important for improving the safety of their operation and for extending their service life [1-6].

For the detection of cracks in rotors, both model-based and experimental approaches have been used by researchers [7-24]. In both approaches, the traditional method of crack identification is the analysis of the vibration signal of the rotor using Fourier transform. The Fourier transform determines the dominant modes of vibration in the form of spectral peaks. From the frequency and magnitude of the peaks, the presence of a crack may be detected. A crack in a rotor introduces a local flexibility to the rotor. The local flexibility is induced by the concentration of strain energy in the vicinity of the crack tip. Because of this local flexibility, the crack may open or close (i.e., breathe) during a complete revolution of the rotor if the rotor is weight dominated. The breathing effect may lead to a parametric excitation of the rotor. If the vibration signal from a cracked rotor is measured and its spectrum is compared to that of a healthy rotor, it is found that the parametric excitation changes slightly only, the magnitudes of the spectral peaks but not the peak frequencies [12]. Thus it is not an easy task to distinguish a cracked rotor from a healthy rotor. To overcome this deficiency, more recent developments include additional excitation of the system such as those induced by active magnetic bearings (AMBs). The AMB acts as an actuator that can apply an external force to the rotating shaft $[12,13,18-22]$. Magnetic bearings also have the ability to vary the applied radial rotor force. If the applied force is periodic, then the presence of a crack, acting as a strong nonlinearity in the system, can generate responses containing additional frequencies that are rational combinations of the rotor spin speed, critical speed of the rotor, and applied forcing frequency. These additional frequencies may be used 
as the signature of a crack and thus may be used for crack identification. Other methods including those based on nonlinear dynamics have been also used for detecting cracks in rotors [25-27].

In this paper a wavelet-based approach is adopted, and a simple quantification procedure is proposed to detect the presence of a crack in a rotating shaft by performing a multiresolution analysis of the vibration signal, based on discrete wavelet transform (DWT). Multiresolution analysis based on DWT has been used for signal analysis in a variety of applications [27-33]. Our detection procedure consists of decomposing the vibration signals into several frequency bands and comparing the rms values of the decomposed signals of the healthy and cracked rotors in a few lowfrequency bands.

It should be emphasized that Fourier transform involves time-averaging of the signal; as a result, it loses the detailed temporal information of the signal. Fourier transform also has a fixed resolution at all frequencies. In contrast, wavelet analysis transforms a signal in the time domain into a timefrequency domain with different resolutions at different signal frequencies. In other words, it provides a multiresolution approach for signal analysis. In the wavelet-based approach, the higher the signal frequency, the finer is the resolution and vice versa.

Several investigators have applied wavelet analysis as a method of detecting cracks in rotors. Wavelet analysis has been performed using (a) continuous wavelet transform (CWT) [7, 8] or (b) discrete wavelet transform (DWT) [34]. The wavelet approach obtains a time-scale decomposition of the signal under consideration using a translation (time) parameter and a scale parameter. In both CWT and DWT, the translation parameter is discrete, whereas the scale parameter is allowed to vary continuously in CWT, but is discrete in DWT. Adewusi and Al-Bedoor [34] used a discrete wavelet transform to analyze the vibration signals of an overhang rotor with a propagating transverse crack. They used the Daubechies $(6 \mathrm{db})$ mother wavelet and presented the results in the form of scalograms and space-scale energy graphs. Their results indicate that at the lowest-frequency band, corresponding to the frequency $1 \mathrm{X}$, the vibration amplitude may increase or decrease depending on the location of the crack and side load; however, the vibration amplitude at the second frequency band, corresponding to the frequency $2 \mathrm{X}$, increases continuously as the crack propagates. The experimental work of Adewusi and AlBedoor [34] does not include magnetic force excitation of the rotor.

In the following development, a DWT-based multiresolution analysis is used to detect the presence of a crack in a rotor both in the presence and absence of magnetic force excitation. The force applied to the shaft is induced by means of an active magnetic actuator. The rms values of the decomposed signal in the three lowest-frequency bands are employed to detect the presence of a crack in the rotor. Our presentation is organized as follows. The experimental procedure is outlined in Section 2 followed by some details of multiresolution wavelet analysis provided in Section 3. In Section 4, the results of multiresolution analysis

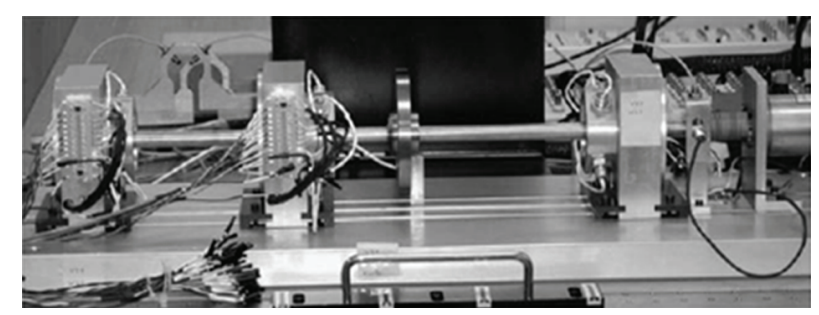

Figure 1: Experimental setup for crack detection in a rotor with active magnetic actuator.

are presented and discussed. Finally, in Section 5, a few concluding remarks are given.

\section{Experimental Procedure}

The experimental setup used in this study is shown in Figure 1. The test rig is equipped with active magnetic bearings (AMBs) which can act as supporting bearings or as actuators to apply forces to the rotating shaft. The rig was designed to operate either on ball bearings or on AMBs. For this study, the rotor is running on ball bearings mounted in support housings (similar to touchdown bearings) which were bolted to the side of the conical magnetic bearing pedestals. The active magnetic actuator is located between the supporting bearings near the unbalance disk. It was calibrated, and currents and fluxes are monitored to control the applied force to the rotating shaft. The actuator is an 8-pole radial design and is equipped with four variable reluctance type position sensors. It can provide specified force actuation in two perpendicular axes, which are rotated $45^{\circ}$ from the vertical. The excitation waveform for the magnetic actuator is generated in MATLAB/SIMULINK environment and transferred to hardware via a dSPACE DS 1103 board.

The shaft diameter is $15.875 \mathrm{~mm}$ and its length is $659 \mathrm{~mm}$. The rotor diameter of active magnetic bearings (not activated in this experiment) and the rotor diameter of radial force actuator are $47.625 \mathrm{~mm}$. The unbalance disk has a diameter of $127 \mathrm{~mm}$ and a thickness of $12.7 \mathrm{~mm}$. The 30 finite element model of the rotor is presented in Figure 2(a) and shows the position of the supporting single row deep groove ball bearings (at nodes 2 and 29), which are assumed isotropic with stiffness $3 \mathrm{MN} / \mathrm{m}$ and damping $10 \mathrm{Ns} / \mathrm{m}$. The notch approximating the crack, having a width of $0.94 \mathrm{~mm}$ ( 0.037 inch) and a depth of $40 \%$ of shaft diameter, is located between the disk and the active magnetic force actuator, at the distance of $292.1 \mathrm{~mm}$ from the left end ball bearing support. It should be noted that such a relatively large notch does not possess all the features of a real crack, including the breathing effect which becomes marginal. The vibration signals are measured at node 15 .

Figure 2(b) shows the Campbell diagram for the rotor system up to a rotor spin speed of $25000 \mathrm{rpm}$. The first resonance speed of the rotor is $2820 \mathrm{rev} / \mathrm{min}(47 \mathrm{~Hz})$, and agrees very well with the experimentally obtained data using either modal approach or measured transfer function. The 


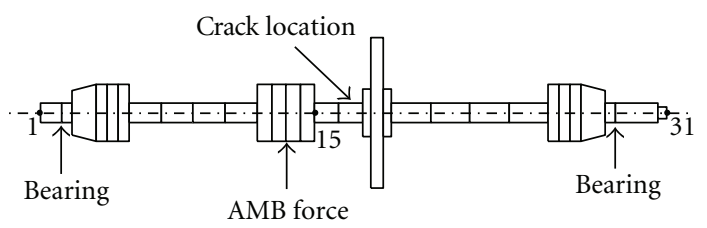

(a)

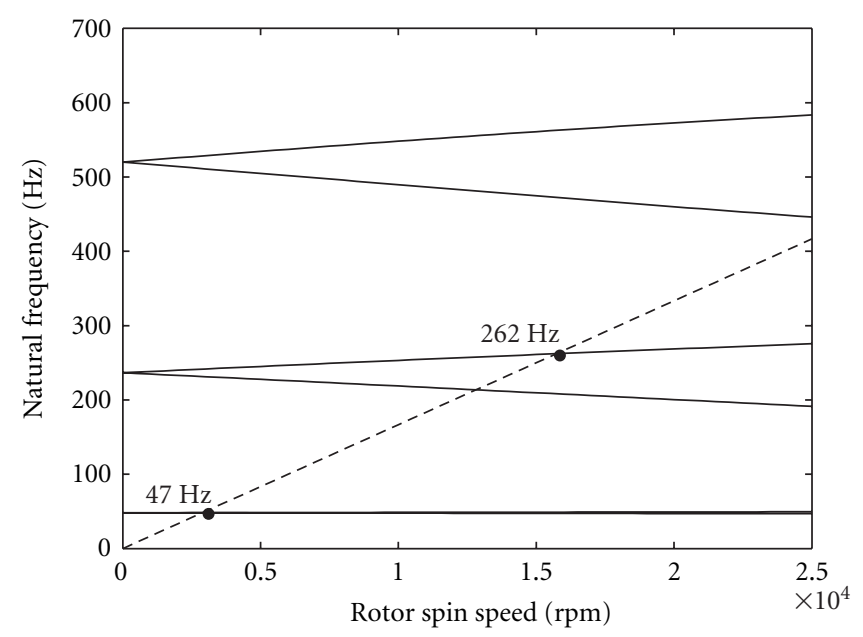

(b)

FIGURE 2: (a) Finite element model of the rotor test rig. (b) Campbell diagram for the undamaged rotor.

other critical speeds for this system are 262, 603, and $875 \mathrm{~Hz}$. The sinusoidal force from the magnetic actuator has peak-to-peak amplitude of $120 \mathrm{~N}$ and frequency of $3780 \mathrm{rev} / \mathrm{min}(63 \mathrm{~Hz})$, while the operating speed of the rotor is maintained at $2200 \mathrm{RPM}(36.67 \mathrm{~Hz})$. The excitation frequency was selected based on the approximate condition for combinational frequencies, that is,

$$
\Omega_{e}=\left|n \Omega-\omega_{i}\right|, \quad \text { for } n= \pm 1, \pm 2, \pm 3, \ldots
$$

The above conditions were derived based on a two degree of freedom Jeffcott rotor model with weight dominance [2022], where $\Omega$ is the rotor speed, $\Omega_{e}$ is the frequency of the magnetic actuator force, and $\omega_{i}$ is the natural frequency of the system. So, in our case, based on the first critical speed and value $n=3$, we have $\Omega_{e}=|(3)(36.67)-47|=63 \mathrm{~Hz}$. Of course, other (corresponding to different $n$ values and higher resonances) excitation frequencies are permissible, but the selected one resulted in the most explicit results.

ControlDesk, an experimental tool, was used to monitor, tune and control the running process, and to capture all the vibration signals. The signals were sampled at $10 \mathrm{kHz}$ and stored on a PC. The experiments were performed at the Center for Rotating Machinery Dynamics and Control (RoMaDyC) at Cleveland State University (see [12] for details).

\section{Multiresolution Wavelet Analysis}

Using discrete wavelet transform, a multiresolution analysis of the vibration signals of the healthy and cracked rotors can be performed as follows [33]. The measured vibration signal is decomposed into several levels with downsampling by a factor of 2 at each successive level. At the first level the signal is decomposed into an approximation component $\left(A_{1}\right)$ and a detail component $\left(D_{1}\right)$. The approximation component, $A_{1}$, is subsequently decomposed into another approximation

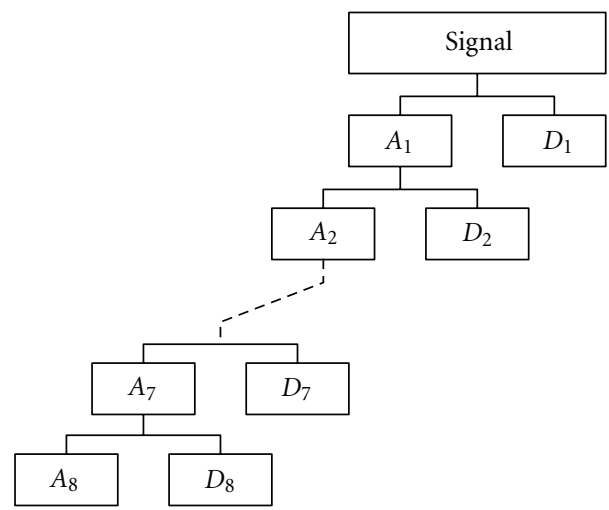

Figure 3: The DWT decomposition showing the various approximation and detail signals at eight levels. The original vibration signal is decomposed into a low-frequency component $\left(A_{1}\right)$ and a high-frequency component $\left(D_{1}\right)$. Each successive approximation is then decomposed into an approximation and a detail component, for example, $A_{1}=A_{2}+D_{2}, A_{2}=A_{3}+D_{3}$, and so on.

component and another detail component, $A_{2}$ and $D_{2}$, respectively, and so on (see Figure 3).

In this manner, the vibration signals from the healthy and cracked rotors are decomposed into eight levels. At each level, the detail component represents a high-frequency band, and the approximation component contains the low frequencies. For example, the detail component $D_{1}$ has the bandwidth $2500-5000 \mathrm{~Hz}$, and the approximation component, $A_{1}$ contains frequencies between 0 and $2500 \mathrm{~Hz}$. We have used a Daubechies wavelet of order 14, as the mother wavelet. Daubechies wavelets have been employed earlier in the detection of cracks in shafts [24], as well as for detecting faults in carbon-fiber reinforced composites [31], and concrete structures [32]. We have specifically chosen the $14 \mathrm{db}$ wavelet due to the fact that its spectrum is much closer to that of a band pass filter, compared to the Daubechies 


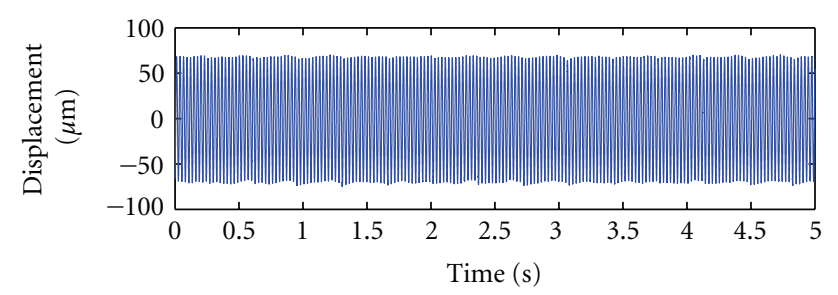

(a)

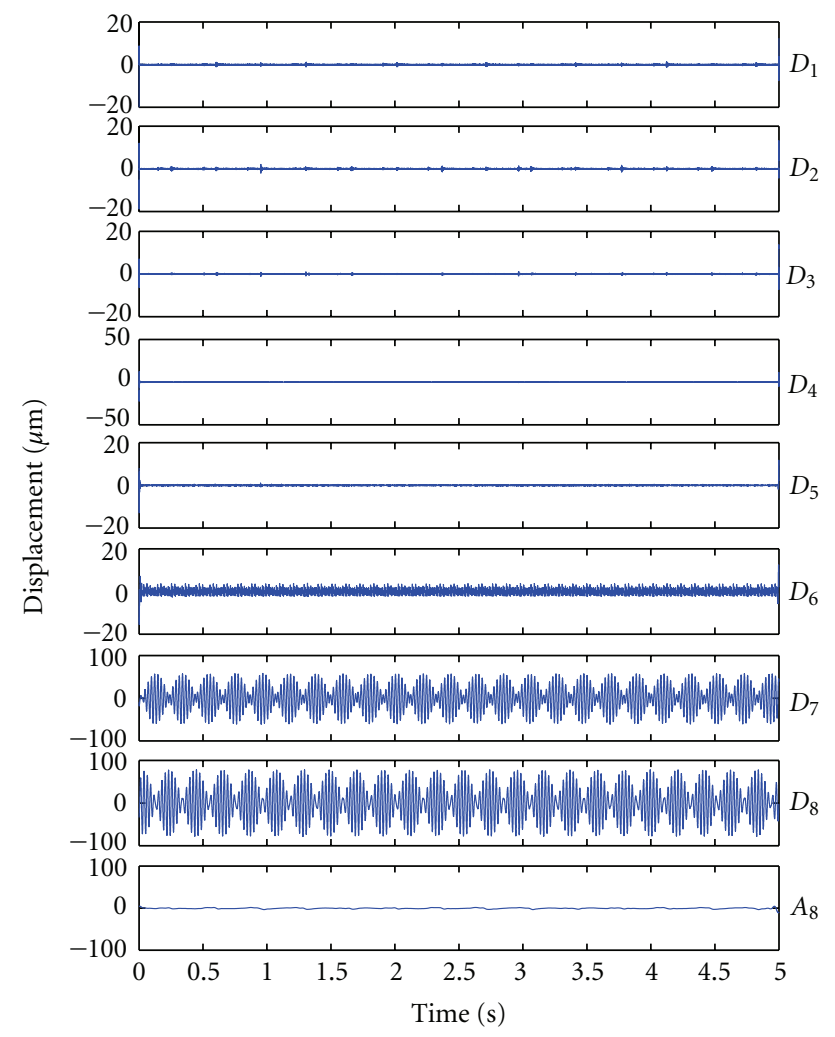

(b)

Figure 4: Time series plot (a) and multiresolution decomposition (b) of the vibration signal for healthy rotor with no excitation.

wavelets of other orders [31]. From the different levels of decomposition, the measured vibration signal, $S(t)$, can be reconstructed as follows:

$$
\begin{aligned}
S(t) & =A_{1}+D_{1}=\left(A_{2}+D_{2}\right)+D_{1}=\left(A_{3}+D_{3}\right)+D_{2}+D_{1} \\
& =\cdots=A_{8}+D_{8}+D_{7}+D_{6}+D_{5}+D_{4}+D_{3}+D_{2}+D_{1} .
\end{aligned}
$$

Following the scheme shown in Figure 3, the detail component, $D_{1}$, represents the highest-frequency band of the decomposition, $D_{2}$ is the next highest-frequency band with half the bandwidth of $D_{1}$, and so forth. If the sampling frequency is $f_{s}$, then the band $D_{n}$ has frequencies between $f_{s} / 2^{n+1}$ and $f_{s} / 2^{n}$, and the approximation, $A_{n}$, has frequency values between 0 and $f_{s} / 2^{n+1}$. In our case, with a sampling frequency of $10 \mathrm{kHz}$, the frequency ranges of the various detail components, $D_{1}$ through $D_{8}$, are as shown in Table 1 . The approximation $A_{8}$ has frequencies between 0 and

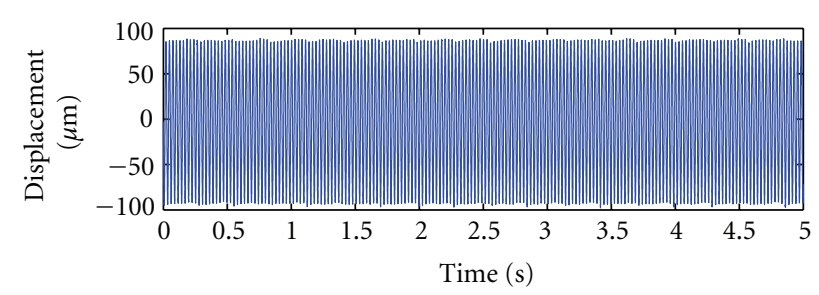

(a)

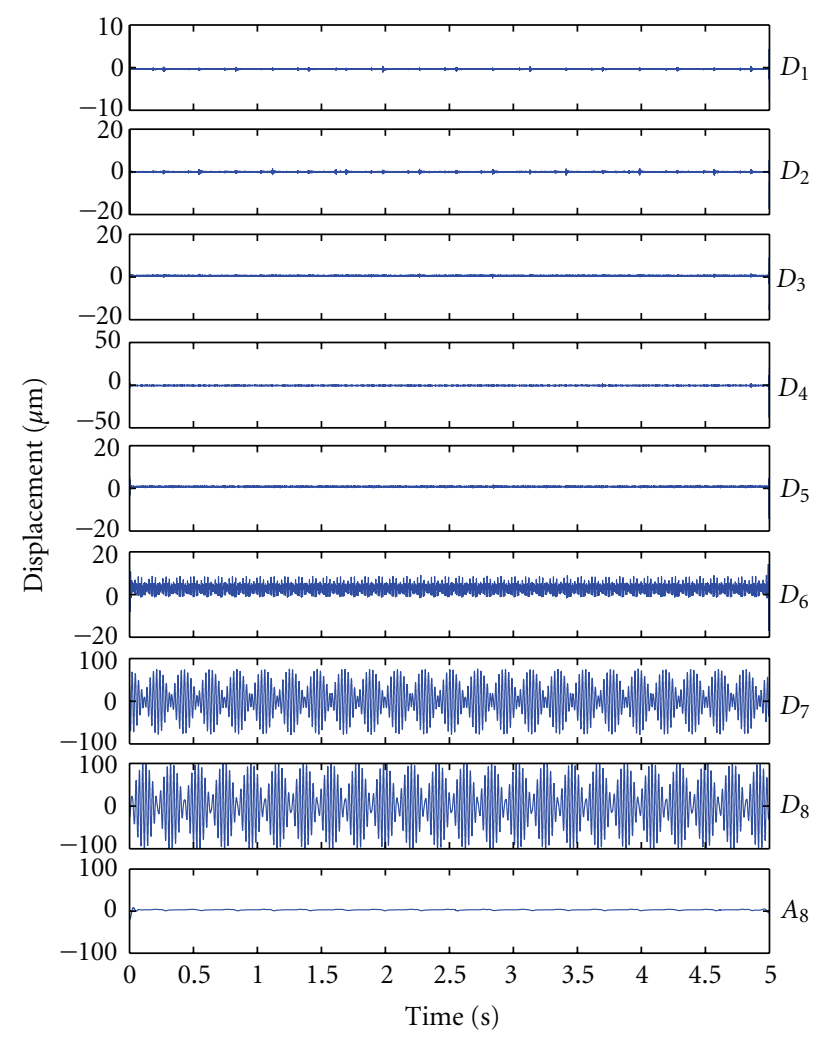

(b)

Figure 5: Time series plot (a) and multiresolution decomposition (b) of the vibration signal for cracked rotor with no excitation.

TABLE 1: Frequency ranges of detail components.

\begin{tabular}{lc}
\hline Detail component & Frequency $(\mathrm{Hz})$ \\
\hline$D_{1}$ & $2500-5000$ \\
$D_{2}$ & $1250-2500$ \\
$D_{3}$ & $625-1250$ \\
$D_{4}$ & $312.5-625$ \\
$D_{5}$ & $156.25-312.5$ \\
$D_{6}$ & $78.125-156.25$ \\
$D_{7}$ & $39.06-78.125$ \\
$D_{8}$ & $19.53-39.06$ \\
\hline
\end{tabular}

19.53 Hz. A detailed account of discrete wavelet transform and multiresolution analysis may be found in [35].

The number of levels to be used in a DWT-based multiresolution analysis is determined by the rotational frequency of the shaft and the sampling rate. The lowest level 


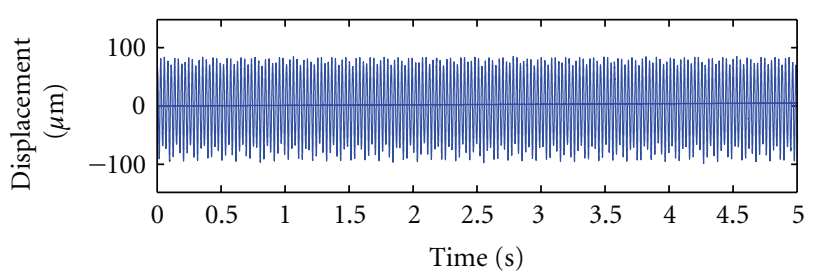

(a)

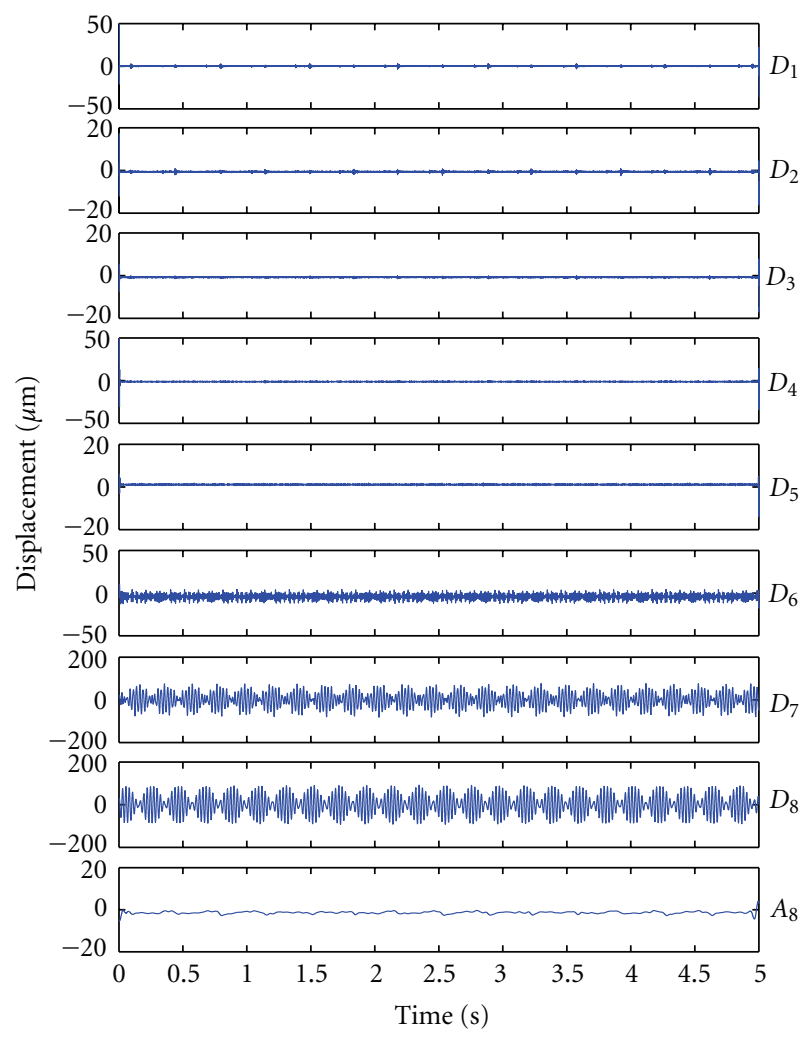

(b)

Figure 6: Time series plot (a) and multiresolution decomposition (b) of the vibration signal for healthy rotor with excitation.

should be chosen such that its detail component has a frequency band that encompasses the rotational frequency. In the present case the rotational frequency is $36.7 \mathrm{~Hz}$, and the sampling rate is $10000 \mathrm{~Hz}$. Based on this sampling frequency the detail component $D_{8}$ lies in the frequency range 19.53$39.06 \mathrm{~Hz}$, approximately. Note that the rotational frequency of $36.7 \mathrm{~Hz}$ falls in this frequency range. Thus it was sufficient to use an eight-level decomposition for the multiresolution analysis.

\section{Results and Discussion}

First we consider the healthy and cracked rotors with no magnetic excitation. The vibration signal of the healthy rotor is depicted in Figure 4(a), and the detail components of the eight-level decomposition are shown in Figure 4(b). The corresponding results for the cracked rotor are illustrated in Figures 5(a) and 5(b), respectively. All vibration signals

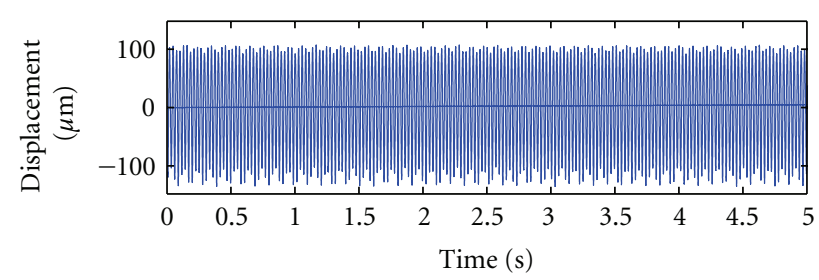

(a)

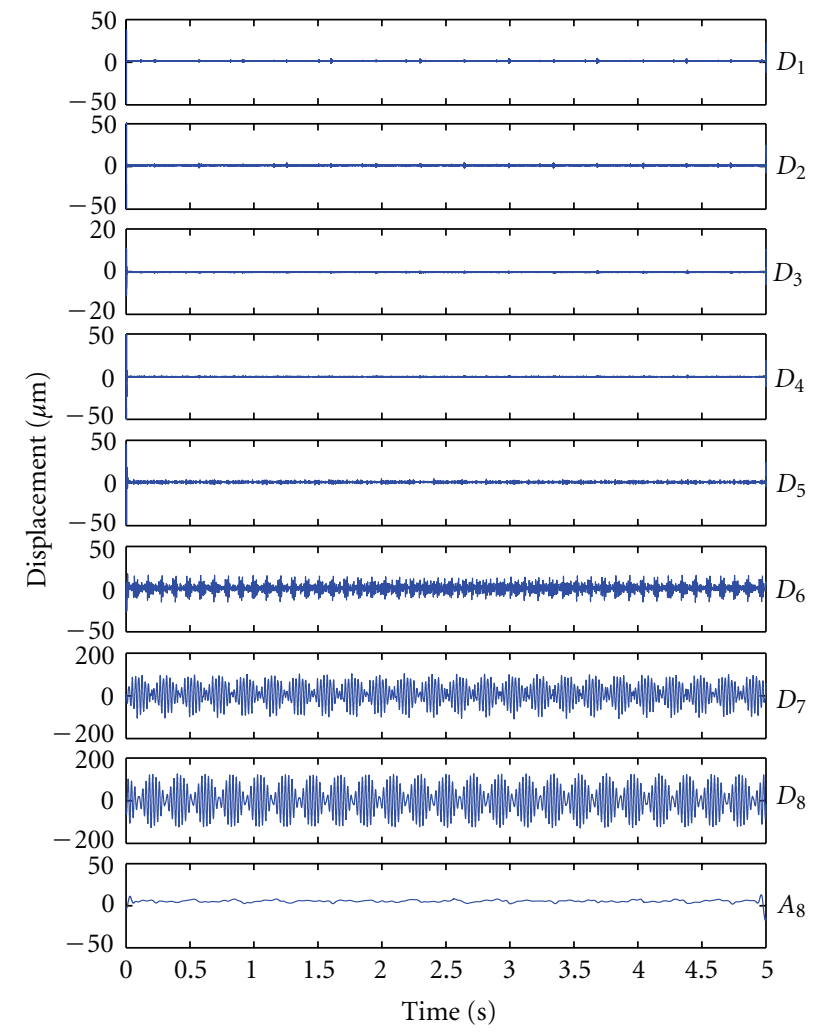

(b)

FIgURE 7: Time series plot (a) and multiresolution decomposition (b) of the vibration signal for cracked rotor with excitation.

are measured by displacement sensors located at node 15 (see Figure 2(a)). It is apparent from Figures 4(b) and 5(b) that the most significant contributions to the signal come from the three lowest-frequency bands: $D_{6}, D_{7}$, and $D_{8}$. The contributions from the other five bands, $D_{1}-D_{5}$, are negligible. Note also that the amplitudes in the approximation, $A_{8}$, which corresponds to the $0-19.53 \mathrm{~Hz}$ frequency band, are very small. The calculated rms values of the amplitudes in the three bands $D_{6}-D_{8}$ are listed in Table 2. It is apparent from this table that in each of these three frequency bands, the rms value of the cracked rotor is larger than that of the healthy rotor.

Next, the vibration signals in the healthy and cracked rotors in the presence of magnetic excitation are examined. For the healthy rotor with magnetic excitation, the vibration signal and its eight-level decomposition are depicted in Figures 6(a) and 6(b), respectively. The corresponding results for the cracked rotor are shown in Figures $7(a)$ and $7(b)$. 
TABLE 2: Comparison of rms values $(\mu \mathrm{m})$ of healthy and cracked rotors with no excitation.

\begin{tabular}{lccc}
\hline Level frequency band & $D_{6} 78.125-156.25 \mathrm{~Hz}$ & $D_{7} 39.06-78.125 \mathrm{~Hz}$ & $D_{8} 19.53-39.06 \mathrm{~Hz}$ \\
\hline Healthy rotor & 1.43 & 29.44 & 38.55 \\
Cracked rotor & 2.16 & 38.04 & 50.71 \\
Percent change & 51.0 & 29.2 & 30.5 \\
\hline
\end{tabular}

TABLE 3: Comparison of rms values $(\mu \mathrm{m})$ of healthy and cracked rotors with excitation.

\begin{tabular}{lccc}
\hline Level frequency band & $D_{6} 78.125-156.25 \mathrm{~Hz}$ & $D_{7} 39.06-78.12 \mathrm{~Hz}$ & $D_{8} 19.53-39.06 \mathrm{~Hz}$ \\
\hline Healthy rotor & 3.23 & 34.01 & 44.15 \\
Cracked rotor & 5.23 & 47.46 & 61.82 \\
Percent change & 61.9 & 39.6 & 40.0 \\
\hline
\end{tabular}

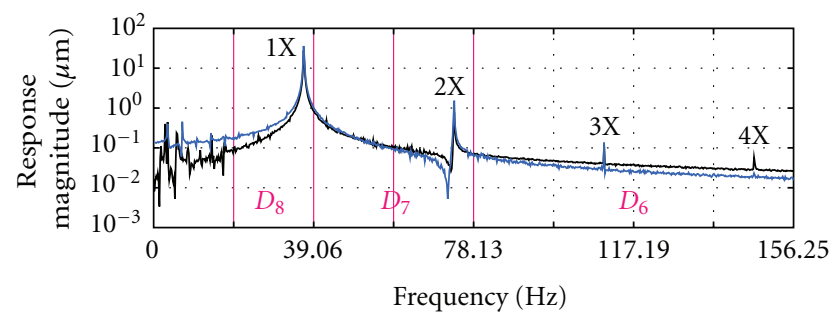

(a)

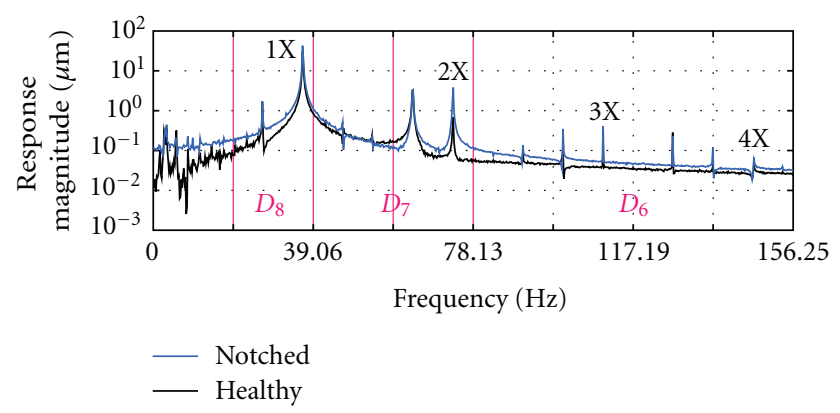

(b)

FIGURE 8: Measured response magnitude of rotor vibrations versus frequency for healthy and notched rotors, without (a) and with (b) external excitation. Rotational frequency is $36.7 \mathrm{~Hz}$, magnetic actuator frequency is $63 \mathrm{~Hz}$, and frequency bands $D_{6}(78.125-$ $156.25 \mathrm{~Hz})$, and $D_{7}(39.06-78.125 \mathrm{~Hz})$, and $D_{8}(19.53-39.06 \mathrm{~Hz})$.

From Figures 6(b) and 7(b), it can be seen that the vibration amplitudes are significant in the three lowest-frequency bands, $D_{6}, D_{7}$, and $D_{8}$. Also, it is found that the rms amplitude value in each of these three bands is larger for the cracked rotor than the healthy rotor (see Table 3 ). In addition, note from Tables 2 and 3 that the difference in the rms values between the healthy and cracked rotors in each of the three lowest-frequency bands is more pronounced in the presence of magnetic excitation than that with no magnetic excitation.

It should be pointed out that the three lowest-frequency bands, $D_{6}-D_{8}$, encompass the frequencies from $39.06 \mathrm{~Hz}$ to $156.25 \mathrm{~Hz}$. Clearly, this frequency range covers the peak frequencies $1 \mathrm{X}-4 \mathrm{X}$ and all other frequency peaks that fall in between, as found by Fourier transform [12] and presented here in Figure 8 with the denoted frequency bands, $D_{6}-D_{8}$. Figure 8(a) shows the measured response at the node 15 of the machine with the damaged (notched) and healthy rotor due to the residual unbalance. The response is characterized by a major peak at the synchronous frequency of $36.7 \mathrm{~Hz}$. The noise-induced harmonics of the spin speed $(2 \mathrm{X}, 3 \mathrm{X}, \ldots)$ can also be seen in the response but their magnitude is very small compared to the $1 \mathrm{X}$ frequency component (note the logarithmic scale). It can be observed that the response magnitude is higher almost at all frequencies for the damaged machine. Figure 8(b) compares the measured rotor response of the machine with the damaged (notched) and healthy rotor due to the residual unbalance and the externally applied magnetic force excitation having the frequency of $63 \mathrm{~Hz}$ and amplitude of $120 \mathrm{~N}$. The rotor spin speed, its harmonics $(1 \mathrm{X}, 2 \mathrm{X}, 3 \mathrm{X}, \ldots)$ and the actuator frequency of $63 \mathrm{~Hz}$ can be noted. In addition, there are visible peaks of combination resonances at 26.3, 63, 83.6, 99.7, 120.3 and $136.3 \mathrm{~Hz}$.

Thus, the applied wavelet analysis includes all spectral peaks that are created by combination resonances due to magnetic excitation. In other words, the spectral content of the vibration signal under magnetic excitation is accurately captured by the DWT-based multiresolution analysis performed here.

\section{Concluding Remarks}

In this study, the dynamics of a simple rotating system with and without a transverse crack in the shaft has been investigated using a multiresolution analysis. The scenario with or without external force excitation has been examined. In this approach, the vibration signal of the rotor is decomposed into eight frequency bands in terms of approximation and detail components. The results show that the rms values of the detail components in the three lowest-frequency bands are higher for the cracked rotor than the healthy rotor, both in the presence or absence of external force excitation. Furthermore, the difference in rms values between a healthy and cracked rotor is more pronounced in the presence of external force excitation. These results indicate that the multiresolution approach can be used to distinguish the healthy and cracked rotor responses. The advantage of this method is that it provides a simple quantification procedure 
based on the rms amplitude values of the vibration signal in different frequency bands. Thus, multiresolution analysis using a discrete wavelet transform suggests an alternative approach to Fourier analysis for structural health monitoring of cracked rotors.

\section{Acknowledgments}

This research has been funded by NASA's "Research Opportunities in Aeronautics," Grant no. NNX08AC31A. The authors would like to thank the graduate students Alex Pesch and Adam Wroblewski at Cleveland State University for their help in obtaining experimental data.

\section{References}

[1] R. Gasch, "A survey of the dynamic behaviour of a simple rotating shaft with a transverse crack," Journal of Sound and Vibration, vol. 160, no. 2, pp. 313-332, 1993.

[2] A. D. Dimarogonas, "Vibration of cracked structures: a state of the art review," Engineering Fracture Mechanics, vol. 55, no. 5, pp. 831-857, 1996.

[3] A. W. Doebling, C. R. Farrar, M. B. Prime, and D. W. Shevitz, "Damage identification and health monitoring of structural and mechanical systems from changes in their vibration characteristics: a literature review," Tech. Rep. LA-13070-MS, Los Alamos National Laboratory, Los Alamos, New Mexico, 1996.

[4] G. Sabnavis, R. G. Kirk, M. Kasarda, and D. Quinn, "Cracked shaft detection and diagnostics: a literature review," Shock and Vibration Digest, vol. 36, no. 4, pp. 287-296, 2004.

[5] Y. Ishida, "Cracked rotors: industrial machine case histories and nonlinear effects shown by simple Jeffcott rotor," Mechanical Systems and Signal Processing, vol. 22, no. 4, pp. 805-817, 2008.

[6] F. F. Ehrich, Handbook of Rotordynamics, Kriegar, Malabar, Fla, USA, 1999.

[7] S. Prabhakar, A. S. Sekhar, and A. R. Mohanty, "Detection and monitoring of cracks in a rotor-bearing system using wavelet transforms," Mechanical Systems and Signal Processing, vol. 15, no. 2, pp. 447-450, 2001.

[8] A. S. Sekhar, "Crack detection through wavelet transform for a run-up rotor," Journal of Sound and Vibration, vol. 259, no. 2, pp. 461-472, 2003.

[9] A. S. Sekhar, "Crack identification in a rotor system: a modelbased approach," Journal of Sound and Vibration, vol. 270, no. 4-5, pp. 887-902, 2004.

[10] A. S. Sekhar, "Model-based identification of two cracks in a rotor system," Mechanical Systems and Signal Processing, vol. 18, no. 4, pp. 977-983, 2004.

[11] J. E. T. Penny and M. I. Friswell, "Simplified modeling of rotor cracks," in Proceedings of the ISMA 27, pp. 607-615, Leuven, Belgium, 2002.

[12] J. T. Sawicki, M. I. Friswell, A. H. Pesch, and A. Wroblewski, "Condition monitoring of rotor using active magnetic actuator," in Proceedings of the ASME Turbo Expo: Power for Land, Sea and Air, Berlin, Germany, June 2008, paper no. GT20085116.

[13] J. T. Sawicki, "Rotor crack detection using active magnetic bearings," Solid State Phenomena, vol. 144, pp. 9-15, 2009.

[14] J. T. Sawicki, X. Wu, G. Y. Baaklini, and A. L. Gyekenyesi, "Vibration-based crack diagnosis in rotating shafts during acceleration through resonance," in Nondestructive Evaluation and Health Monitoring of Aerospace Materials and Composites II, vol. 5046 of Proceedings of SPIE, pp. 1-10, 2003.

[15] X. Wu, M. I. Friswell, J. T. Sawicki, and G. Y. Baaklini, "Finite element analysis of coupled lateral and torsional vibrations of a rotor with multiple cracks," in Proceedings of the ASME Turbo Expo, vol. 4, pp. 841-850, Reno-Tahoe, Nev, USA, 2005, paper no. GT2005-68839.

[16] I. Imam, S. H. Azzaro, R. J. Bankert, and J. Scheibel, "Development of an on-line rotor crack detection and monitoring system," Journal of Vibration, Acoustics, Stress, and Reliability in Design, vol. 111, no. 3, pp. 241-250, 1989.

[17] T. Iwatsubo, S. Arii, and J. Lund, "Detection of a transverse crack in a rotor shaft by adding an external force," in Proceedings of the IMechE Vibrations in Rotating Machinery, pp. 275-282, 1992, paper no. C432/093.

[18] R. R. Humphris, "A device for generating diagnostic information for rotating machinery using magnetic bearings," in Proceedings of the Magnetic Bearings, Magnetic Drives, and Dry Gas Seals Conference \& Exhibition (MAG '92), pp. 123-135, Alexandria, Va, USA, 1992.

[19] C. Zhu, D. A. Robb, and D. J. Ewins, "The dynamics of a cracked rotor with an active magnetic bearing," Journal of Sound and Vibration, vol. 265, no. 3, pp. 469-487, 2003.

[20] D. D. Quinn, G. Mani, M. E. F. Kasarda, T. Bash, D. J. Inman, and R. G. Kirk, "Damage detection of a rotating cracked shaft using an active magnetic bearing as a force actuator-analysis and experimental verification," IEEE/ASME Transactions on Mechatronics, vol. 10, no. 6, pp. 640-647, 2005.

[21] J. E. T. Penny, M. I. Friswell, and C. Zhou, "Condition monitoring of rotating machinery using active magnetic bearings," in Proceedings of the ISMA International Conference on Noise and Vibration Engineering, pp. 3497-3506, Leuven, Belgium, 2006.

[22] G. Mani, D. D. Quinn, and M. Kasarda, "Active health monitoring in a rotating cracked shaft using active magnetic bearings as force actuators," Journal of Sound and Vibration, vol. 294, no. 3, pp. 454-465, 2006.

[23] G. T. Zheng, "Vibration of a rotor system with a switching crack and detection of the crack," Journal of Engineering for Gas Turbines and Power, vol. 120, no. 1, pp. 149-154, 1998.

[24] M.-C. Wu and S.-C. Huang, "In-plane vibration and crack detection of a rotating shaft-disk containing a transverse crack," Journal of Vibration and Acoustics, vol. 120, no. 2, pp. 551-556, 1998.

[25] J. T. Sawicki, X. Wu, A. L. Gyekenyesi, and G. Y. Baaklini, "Application of nonlinear dynamics tools for diagnosis of cracked rotor vibration signatures," in Nondestructive Evaluation and Health Monitoring of Aerospace Materials, Composites, and Civil Infrastructure IV, vol. 5767 of Proceedings of SPIE, pp. 286-297, 2005.

[26] G. Litak, J. T. Sawicki, and R. Kasperek, "Cracked rotor detection by recurrence plots," Nondestructive Testing and Evaluation, 2008, In press.

[27] D. Guo and Z. K. Peng, "Vibration analysis of a cracked rotor using Hilbert-Huang transform," Mechanical Systems and Signal Processing, vol. 21, no. 8, pp. 3030-3041, 2007.

[28] H. Adeli, Z. Zhou, and N. Dadmehr, "Analysis of EEG records in an epileptic patient using wavelet transform," Journal of Neuroscience Methods, vol. 123, no. 1, pp. 69-87, 2003.

[29] J. R. Kulkarni, "Wavelet analysis of the association between the Southern Oscillation and the Indian summer monsoon," International Journal of Climatology, vol. 20, no. 1, pp. 89-104, 2000. 
[30] J. B. Ramsey and C. Lampart, "Decomposition of economic relationships by timescale using wavelets: money and income," Macroeconomic Dynamics, vol. 2, no. 1, pp. 49-71, 1998.

[31] H. Lundstedt, "Wavelet reconstructions of solar magnetic activity," Journal of Physics IV, vol. 139, pp. 167-174, 2006.

[32] A. K. Sen, "Multiscale analysis of riverflow variability in the British isles," submitted for publication.

[33] G. Qi, A. Barhorst, J. Hashemi, and G. Kamala, "Discrete wavelet decomposition of acoustic emission signals from carbon-fiber-reinforced composites," Composites Science and Technology, vol. 57, no. 4, pp. 389-403, 1997.

[34] S. A. Adewusi and B. O. Al-Bedoor, "Wavelet analysis of vibration signals of an overhang rotor with a propagating transverse crack," Journal of Sound and Vibration, vol. 246, no. 5, pp. 777-793, 2001.

[35] H. Hatanaka, Y. Kawano, N. Ido, M. Hato, and M. Tagami, "Ultrasonic testing with advanced signal processing for concrete structures," Nondestructive Testing and Evaluation, vol. 20, no. 2, pp. 115-124, 2005. 

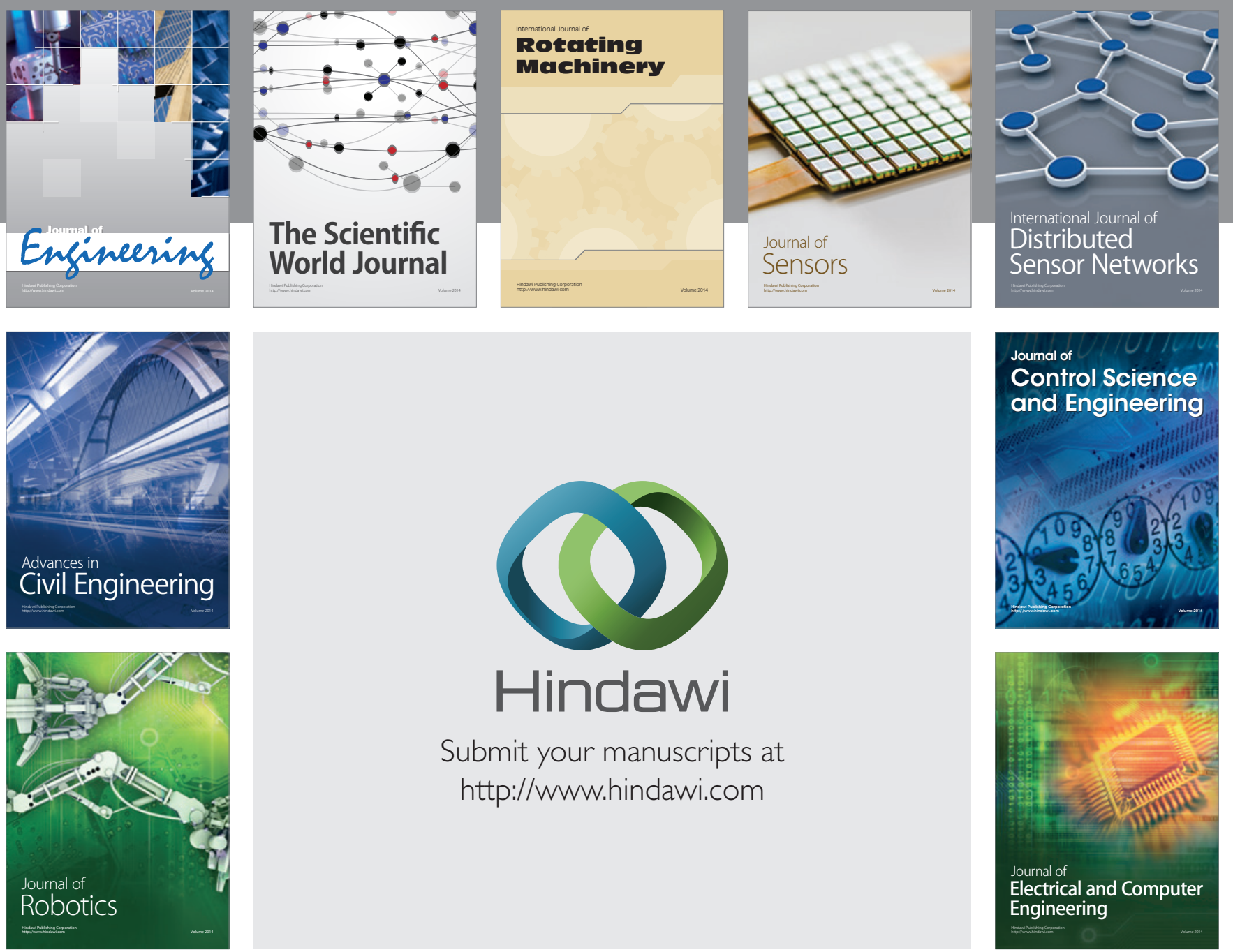

Submit your manuscripts at

http://www.hindawi.com
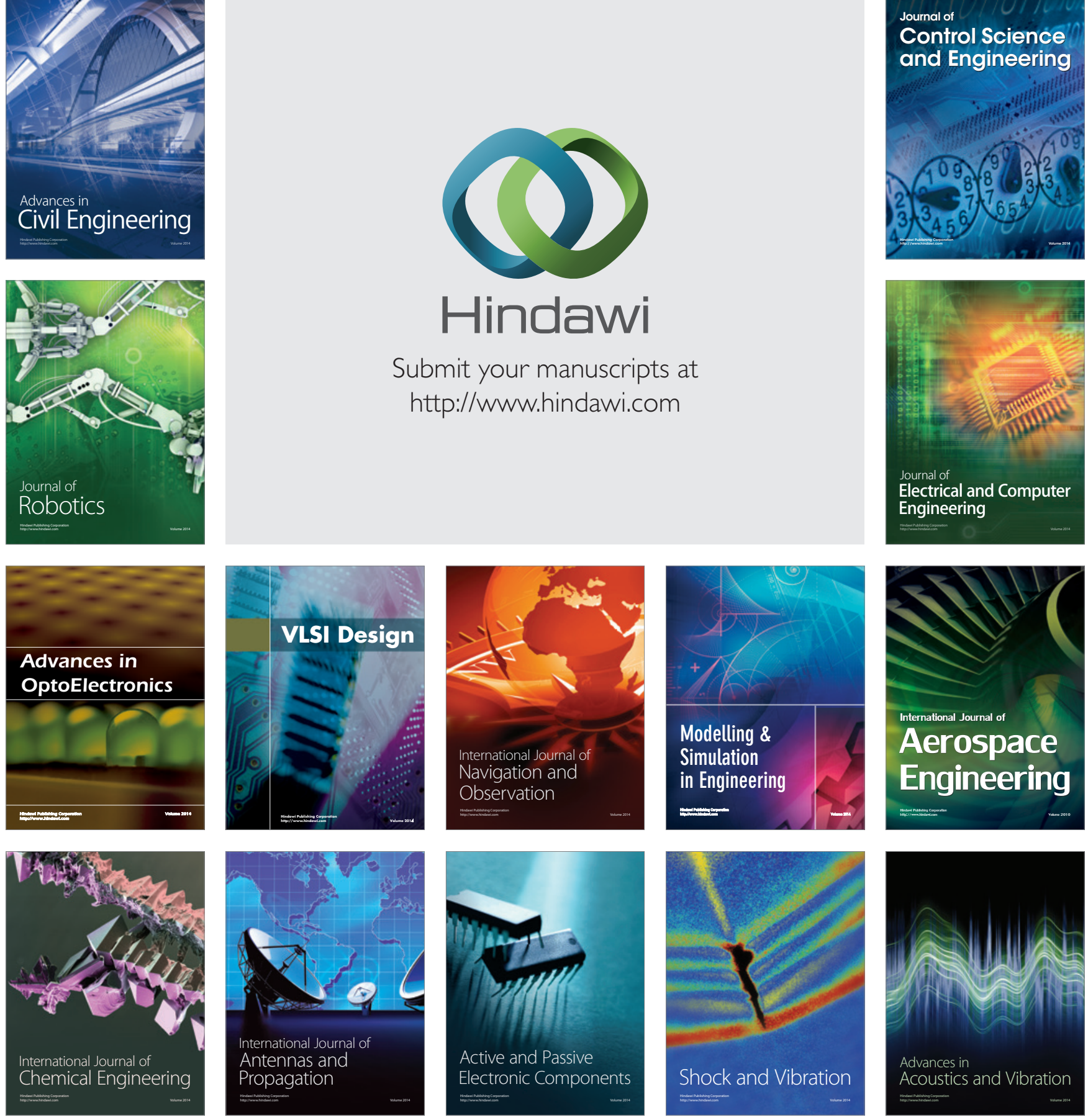